\title{
Dr. Henry L. Coit $\uparrow$
}

Die wieder angebahnten ärztlichen Verbindungen mit Amerika brachten erst jetzt die Kunde von dem am 12. März 1917 eingetretenen Tode von Dr. Henry L. Coit.

Er war der Begründer der „medizinischen Milchkom. missionen" in den Vereinigten Staaten und der Säuglingsfürsorge in seinem engeren Heimatlande New-Jersey. Jene bestanden ursprünglich aus der freien Vereinigung von Hygienikern, Püdiatern und Tierärzten, um zur rationellen Säuglingsernährung und $\mathrm{Be}$ kämpfung der hohen Sterblichkeit eine einwandfreie, die „certified“ Milch bereitzustellen. Im Jahre 1909 wurden die aus einer zehnjährigen Erfahrung gesammelten Bestimmungen zum Gesetze erhoben. Dasselbe geht weniger mit Strafen als mit Aneiferung durch das "Scorecard (Punkt-) System" vor und entspricht dem praktischen, auf den Wettbewerb vorwiegend gerichteten Sinn der Amerikaner. So wurden die Städte mit Milch von reinster Beschaffenheit reichlich versorgt. Diese Art von Milchkontrolle wirkte fördernd auf die Milchproduktion zurück, deren sogar überseeische volkswirtschaftliche Bedeutung das deutsche Mitteleuropa in den Kriegs- und Hungerjahren durch die Ersatzernährung mit Kondensmilch kennenlernte.

Die Säuglingsfürsorge als soziales Hilfswerk wurde erst im Anschluß an die vorbereitende Tätigkeit der medizinischen Milchkommissionen eingerichtet.

Auf dem Gebiete der Kinderheilkunde war Coit, der von alter amerikanischer Herkunft war, durch seine vornehmen Charaktereigenschaften in Gemeinschaft mit seinem organisatorischen Talent und Eifer zur Führung berufen. Er ist auch ein Opfer dieser edlen Veranlagung geworden, denn er arbeitete - die Abnahme seiner Herzkraft nicht achtend - an der Leitung der Maßnahmen zur Bekämpfung der 1916 herrschenden Poliomyelitisepidemie, sich aufopfernd, mit, bis ihn eine Lungenentzündung nach dreitägigem Krankenlager dahinraffte. „Sein Herz wünschte zu ruhen." Mit diesen von seinem Arzte am Sterbebette an die trauernde Familie gerichteten Trostesworten ist Coit als Mensch von Herzensgüte und harmonischer Seelenruhe treffend gekennzeichnet.

Seine Freunde in der deutschen Pädiatrie werden ihm ein ehrendes Andenken bewahren!

Dr. Siegfried Weiss.

Wien, Maximilianstraße 5. 